Faculty of Science

Faculty Publications

This is a post-print copy of the following article:

Effects of stem-injected gibberellins and 6-benzylaminopurine on phytohormone profiles and cone yield in two lodgepole pine genotypes

Lisheng Kong, Patrick von Aderkas, Irina Zaharia

June 2018

The final publication is available at Springer via:

https://doi.org/10.1007/s00468-018-1670-7

Citation for this paper:

Kong, L., von Aderkas, P. \& Zaharia, L.I. (2018). Effects of stem-injected gibberellins and 6-benzylaminopurine on phytohormone profiles and cone yield in two lodgepole pine genotypes. Trees, 32(3), 765-775. 


\title{
Effects of stem-injected gibberellins and 6-benzylaminopurine on phytohormone profiles and cone yield in two lodgepole pine genotypes
}

\author{
Lisheng Kong $\left(1,3^{*}\right)$, Patrick von Aderkas (1), L. Irina Zaharia (2)
}

${ }^{1}$ Centre for Forest Biology, Department of Biology, University of Victoria, 3800 Finnerty Rd., Victoria, BC, Canada V8W 3N5

${ }^{2}$ National Research Council of Canada, 110 Gymnasium Place, Saskatoon, SK, Canada S7N 0W9

${ }^{3}$ Beijing Advanced Innovation Center for Tree Breeding by Molecular Design, College of Biological Science and Biotechnology, Beijing Forestry University, 100083, Beijing, Peoples' Republic of China

* Lisheng Kong (Corresponding author)

E-mail: Ikong@uvic.ca

Running title: Phytohormones and cone induction in lodgepole pine 


\begin{abstract}
Effects of exogenously applied gibberellins (GAs) and 6-benzylaminopurine (BA) on profiles of phytohormones and some of their metabolites relative to controls in long-shoot buds of lodgepole pine (Pinus contorta Dougl. ex Loud. var. latifolia Engelm.) were analyzed during cone bud initiation and differentiation. Differential responses in phytohormones and in cone yield were observed in ramets of the two tested genotypes (478 and 276 ) to stem-injected mixtures of $\mathrm{GA}_{4}$ and $\mathrm{GA}_{7}\left(\mathrm{GA}_{4 / 7}\right)$ and/or $\mathrm{BA}$. Injected $\mathrm{GA}_{4 / 7}$ affected bud concentrations of $\mathrm{GA}_{4}$ and $\mathrm{GA}_{7}$, Injected PGRs, with the exception of $\mathrm{BA}$ injection, decreased concentrations of abscisic acid (ABA) and ABA glucose-ester at weeks 5 and/or week 7. Internal concentrations of trans-zeatin riboside ( $t$-ZR) increased in response to all treatments at week 3 in genotype 276 . In genotype $478, t$-ZR only increased with treatments of $B A$ or $\mathrm{GA}_{4 / 7}$ plus BA. Dihydrozeatin riboside concentrations increased in response to $\mathrm{GA}_{4 / 7}$ plus $B A$ treatment at week 7 in genotype 276. Concentrations of isopentenyl adenosine declined with treatments of $\mathrm{GA}_{4 / 7}$ and $\mathrm{GA}_{4 / 7}$ plus $\mathrm{BA}$ in genotype 276 at week 5. In genotype 478, a similar decrease was caused by $\mathrm{GA}_{4 / 7}$ plus $\mathrm{BA}$ treatment. For both genotypes, the highest ratio of zeatin-type cytokinins to isopentenyl-type cytokinins occurred at weeks 5 and 7 after injection with $\mathrm{GA}_{4 / 7}$ plus BA. Stem-injection of $\mathrm{GA}_{4 / 7}$, especially in combination with $\mathrm{BA}$, increased female cone yields significantly in genotype 276, but not in genotype 478 .
\end{abstract}

\title{
Key words:
}

lodgepole pine, phytohormone, gibberellin $\mathrm{GA}_{4}+\mathrm{GA}_{7}$, 6-benzylaminopurine, stem-injection, female cone yield 


\section{Abbreviations:}

High-performance liquid chromatography-electrospray ionization tandem mass spectrometry, HPLC-ESI-MS/MS; multiple-reaction monitoring, MRM; abscisic acid, ABA; 6-

benzylaminopurine, BA; gibberellin, GA; phaseic acid, PA; dihydrophaseic acid, DPA; 7'hydroxy ABA, 7'-OH ABA; neophaseic acid, neoPA; abscisic acid glucose ester, ABA-GE; trans-zeatin, $t$-Z; trans-zeatin riboside, $t$-ZR; trans-zeatin-O-glucoside, $t$-Z-O-Glu;

dihydrozeatin, dhZ; dihydrozeatin riboside, dhZR; isopentenyl, iP; isopentenyl adenine, 2iP; isopentenyl adenosine, iPA. 


\section{Introduction}

Seed yield from seed orchards of coniferous trees depends on physiological responses to abiotic and biotic factors. Seed number can be limited by poor growing conditions during a particular year, as well as by nutrition and water availability. In optimal conditions, seed number may be increased in some species much more than in others. Douglas-fir, for example, naturally produces super-abundant cone crops during particularly propitious years: these are known as mast years. Other species such as lodgepole pine have less variable cone crops (Herrera et al. 1998). To improve seed output in such trees, orchard management practices attempt to optimize nutrition, irrigation and pest reduction. However, a healthy tree is not necessarily a productive tree in terms of cone production. To increase cone production, physiological intervention of the tree is sometimes required. This may be in the form of physical treatments such as root pruning and stem girdling, but it may also include application of plant growth regulators (PGRs). Successful cone induction relies on multiple factors, such as the species of tree, type and dosage of PGRs, timing and method of PGR application, and physiological condition of the trees (Bonnet-Masimbert 1987; Smith and Greenwood 1995; Kong et al. 2016).

In British Columbia, there are many seed orchards that include lodgepole pine (Pinus contorta Dougl. ex Loud. var. latifolia Engelm.), one of the most economically important species in Canada (McDougal 1973). Millions of hectares of lodgepole pine trees in Canada and United States have been and continue to be lost to the current mountain pine beetle epidemic (Amman and Schmitz 1988; Fettig et al. 2014). Lodgepole pine is a limited cone producer. This is because its cone buds are not found at different locations along branches, as is the case for Douglas-fir and cedars, but only differentiate at branch tips, i.e. in long- 
shoot buds. Furthermore, cones of lodgepole pine at the branch tips are normally strongly segregated by gender. A few female cones develop at the distal end of the new long-shoot, whereas numerous pollen cones are formed to the proximal end.

Altering the number of cones in the long shoots of pines occurs if the trees are treated with a mixture of gibberellins of $\mathrm{GA}_{4}$ and $\mathrm{GA}_{7}$, or $\mathrm{GA}_{4 / 7}$ (Marquarda, b; Hanover 1984; Ross and Pharis 1987). Exogenously applied $\mathrm{GA}_{4}$ and $\mathrm{GA}_{7}$ are more effective than $\mathrm{GA}_{3}$ in promoting flowering in coniferous species due to their less polar molecular structures (Pharis et al., 1987). Other PGRs, such as cytokinin, have also been shown to enhance female cone-bud formation (Wakushima 2004). However, the use of other PGRs has met with mixed results. When Smith and Greenwood (1995) stem-injected black spruce trees with 6benzylaminopurine (BA), a cytokinin, either with or without $\mathrm{GA}_{4 / 7}$ the effects in cone induction were slightly promotive and even negative. However, cone induction responded much more positively to these PGR mixtures in Sitka spruce (Tompsett 1977) and Douglas-fir (Zaerr and Bonnet-Masimbert 1987). Most recently, Kong et al. (2016) working on lodgepole pine reported success in inducing female cone clusters with bud paste containing a mixture of gibberellins and cytokinin, i.e. $\mathrm{GA}_{4 / 7}$ and thidiazuron (TDZ, N-phenyl N' 1, 2, 3-thidiazol-5-yl urea). They measured the effects of exogenous application of PGRs on endogenous phytohormone profiles. Well-timed PGR paste application to developing long-shoot buds altered endogenous phytohormone profiles prior and during cone bud initiation and differentiation. PGR treatments resulted in higher endogenous concentrations of zeatin (Z)type cytokinins and lower concentrations of abscisic acid (ABA) and its metabolite, ABA glucosyl ester (ABA-GE). This corroborates earlier investigations (Kong et al. 2011, 2012) in which higher concentrations of (Z)-type cytokinins and lower concentrations of ABA favoured 
female cone formation. Kong et al. (2016) found that paste application altered both the number and location of female cones. Female cones appeared in large numbers in the proximal portion of the long-shoot bud normally reserved for male cone formation.

Plant growth regulators applied in paste form, or as a spray, or by injection into the stem. The major advantages of bud paste treatment include 1) slower release of PGRs from the paste compared with stem-injection or crown-spray; 2) site-specific application to longshoot buds; 3) minimal damage. For these reasons, bud-paste treatment is preferred during the research and method development phase. However, bud paste treatment is labourintensive and poorly suited to operational applications in large seed orchards. Larger scale application favours the stem-injection method because 1) higher efficiency is achieved, since stem-injection distributes PGRs throughout the entire crown (Marquard and Hanover 1984a,b); 2) preparation of PGR solutions is cheaper for stem-injection than complex preparation of paste; 3) subsequent rainy weather has little effect on stem injection, but can cause bud paste treatments to fail.

Phytohormone concentrations of developing long-shoot buds before and after PGR injection were investigated in two lodgepole pine genotypes. The objective of our research was twofold: 1. to investigate the effect of stem injection of PGRs on changes of endogenous concentrations of GAs, cytokinins, and ABA, as well as some of their metabolites; and 2) to determine whether there was an effect of stem injection on cone yield. Phytohormone concentrations were determined by high performance liquid chromatography-electrospray ionization tandem mass spectrometry (HPLC-ESI-MS/MS) with multiple reaction monitoring (MRM) mode (Chiwocha et al. 2003, 2005). 


\section{Material and Methods}

\section{Plant Materials}

Twenty-four ramets of each genotype (nos. 276 and 478) were chosen from a seed orchard owned by Vernon Seed Orchard Company, Vernon, British Columbia $\left(50^{\circ} 13^{\prime} \mathrm{N}, 119^{\circ} 19^{\prime}\right.$ W). These genotypes had been characterized as moderate female cone producers on the basis of cone production performance over a number of years. Ramets of similar size, i.e. with an average stem diameter of $75 \mathrm{~mm}$, were selected for use. We used 16-year-old trees that were 14 to 20 feet in height. They had not previously been subjected to cone induction treatments. To avoid destructive effects on sample trees, ramets were divided into two groups that received the same experimental treatments: the first group was used to evaluate phytohormone profiles and the second group to evaluate cone production. Cone yield was assessed the spring following PGR treatment. The number of female cones per tree was counted.

\section{$G A$ and $B A$ treatments}

Four stem-injection treatments were used: $\mathrm{GA}_{4+7}, \mathrm{BA}, \mathrm{GA}_{4+7}$ plus BA and the control. The mixture of GAs, $\mathrm{GA}_{4 / 7}$, for this study was originally provided to Vernon Seed Orchard Company by the University of Calgary (Calgary, Alberta, Canada). The GA mixture was dissolved in methanol at a concentration of $40 \mathrm{mg} \mathrm{ml}^{-1}$. The ratio of $\mathrm{GA}_{4}$ to $\mathrm{GA}_{7}$ was approximately 4:1. 6-benzylaminopurine (Caisson Laboratories, North Logan, UT, USA) was dissolved in $1 \mathrm{~N} \mathrm{KOH}$ and diluted to a final concentration of $40 \mathrm{mg} \mathrm{ml}^{-1}$. Solutions were steminjected into small holes made with a drill. The holes were $6 \mathrm{~mm}$ in diameter and approximately $40 \mathrm{~mm}$ in depth and at an angle of approximately $45^{\circ}$ to the stem (Kong et al. 
2008). Solutions of $\mathrm{GA}_{4+7}$, $\mathrm{BA}$ were injected to separate holes at the same time point, i.e. one after another. The holes were 0.6 to $0.75 \mathrm{~m}$ above the ground. All PGR treatments were applied in late spring before cone-bud differentiation had occurred. In the North Okanagan Valley of British Columbia cone-bud differentiation was in late May or early June. New terminal shoots were approximately $2.5 \mathrm{~cm}$ in length. Cone yield was measured in spring or early summer of the following year.

Sample collection, processing and storage

Apical bud collection began on the date of PGR injection and continued at regular intervals of one or two weeks for a total of five different time points. Depending on bud size, from 10 to 20 long-shoot buds were collected and pooled from each ramet at each sampling point. Three ramets were used as replicates. Samples were kept frozen in a $-20^{\circ} \mathrm{C}$ freezer for 2 days and then lyophilized in a freeze-drier for a minimum of $48 \mathrm{~h}$. Samples were then sealed in plastic bags and stored at $-20^{\circ} \mathrm{C}$.

\section{Analysis of Phytohormones and Some Hormone Metabolites}

Phytohormone analysis of the long-shoot bud tissue was according to previously established methods (Kong et al. 2008). Quantification of extractable and/or endogenous GAs, cytokinins, $A B A$ and related metabolites was established by stable isotope dilution (Chiwocha et al. 2003). For each phytohormone analyzed, stable deuterium isotope-labeled internal standards of known quantities were added to samples upon extraction. Phytohormones analyzed included 1) endogenous cytokinins [trans-zeatin ( $t$-Z), cis-zeatin (c$Z)$, trans-zeatin riboside (t-ZR), cis-zeatin riboside (c-ZR), dihydrozeatin (dhZ), dihydrozeatin riboside (dhZR), and trans-zeatin-O-glucoside (t-ZOG), cis-zeatin-O-glucoside (c-ZOG), isopentenyl adenosine (iPA), and isopentenyl adenine (2iP)]; 2) several gibberellins, i.e. $\mathrm{GA}_{1}$, 
$\mathrm{GA}_{3}, \mathrm{GA}_{4}$, and $\left.\mathrm{GA}_{7} ; 3\right) \mathrm{ABA}$ and several ABA metabolites [ABA glucose ester (ABA-GE), 7 hydroxy ABA (7'-OH ABA), neo-phaseic acid (neoPA), phaseic acid (PA), and dihydrophaseic acid (DPA)]. Extractable BA was not assessed simultaneously since an isotope-labeled standard was not available.

\section{Experimental design and statistical analysis}

A total of 48 ramets from two genotypes were used. Ramets in the same genotype were divided randomly into two equivalent groups and both groups received the same treatments. One group was used for sampling for hormone analysis and another group was used to evaluate the effects of treatments on cone formation. This was done to avoid destructive effects caused by sampling in the first group. In each group, three trees that received the same treatment were sampled at each time point and analyzed as replicates. Cone induction data was collected from three ramets for each treatment in the following year after PGR treatments.

Phytohormone data from treatments were subjected to one-way analysis of variance (ANOVA) using Minitab statistical software (Minitab, State College, Pennsylvania, USA). The variance was analyzed by Tukey's significant difference with the level of significance at $P<$ 0.05 .

\section{Results}

\section{Effects of stem-injected PGRs on phytohormone profiles}

Gibberellins: Gibberellin levels in samples of day 0, just before PGR application, were low, and only $\mathrm{GA}_{7}, 7.2 \pm 0.3 \mathrm{ng}^{-1} \mathrm{DW}$, was quantified in samples of genotype 276 . The high relative concentrations of GAs were observed in samples of the second time point, i.e. one 
week after GA injection (Fig. 1). Both $\mathrm{GA}_{4}$ and $\mathrm{GA}_{7}$ peaked in samples of week 1 and declined thereafter in genotype 478 , whereas in genotype 276 , these two GAs peaked at week 3 before declining. In samples of BA treatment and the control without GA injection, we found $\mathrm{GA}_{4}$ was undetectable, whereas $\mathrm{GA}_{7}$ was quantified at low levels, i.e. $7-18 \mathrm{ng}^{-1} \mathrm{DW}$. The ratio of GAs changed. Before injection, the ratio of $G_{4}$ to $G A_{7}$ in the mixture of powder was approximately 4:1 (54: 14). One week following $\mathrm{GA}_{4 / 7}$ injection, the ratio of GAs detected in the long shoot buds increased to $5: 1$ and 6:1 in genotypes 478 and 276 , respectively. These ratios peaked at week 3 in both of the genotypes. This ratio then remained with little change in genotype 478 and a slight decrease in genotype 276 until week 7 (Fig. 2). Other $\mathrm{GAs}$, i.e. $\mathrm{GA}_{4}$ and $\mathrm{GA}_{3}$ were below quantifiable limits.

Abscisic acid and metabolites: Following stem injection of $\mathrm{GA}_{4 / 7}$, alone or in combinations with $B A$, endogenous ABA concentrations decreased in both genotypes 276 and 478 by week 7 (Fig. 3). In genotype 478, significant decrease $(P<0.05)$ of ABA started at week 5 (Fig. 3). The largest decrease in ABA concentrations was more than two-fold by treatments of $\mathrm{GA}_{4 / 7}$,or $\mathrm{GA}_{4 / 7}$, plus $\mathrm{BA}$ by week 7 in genotype 276. Concentrations of $\mathrm{ABA}$ showed little change, relative to the control, in the samples with BA treatments in genotype 276 , whereas it was lower in samples by week 7 in genotype 478 (Fig. 3). By the end of the experiment, all concentrations of ABA were lower in treated genotypes than in controls. Similarly, concentrations of ABA-GE were lower in samples of all the treatments in genotype 276 by week 7 (Fig. 4). In genotype 478, concentrations of ABA-GE were decreased by GA injection, alone or in combination with BA, at weeks 5 and 7. Injection of GAs also decreased the concentration of PA, a catabolite of ABA, at week 7 in genotype 276 (Data not shown). In 
genotype 478, PA was quantifiable in only a few samples. Other ABA catabolites, i.e. DPA, 7'-OH ABA and neoPA, were generally below quantifiable limits.

Cytokinins: Among all the quantifiable Z-type cytokinins, concentrations of $t$-ZR and $d h Z R$ were the highest in both of the pine genotypes. In genotype $276, t$-ZR concentrations were significantly higher at week 3 in samples of treatments with $\mathrm{GA}_{4 / 7}, \mathrm{BA}$, or the combination of $\mathrm{GA}_{4 / 7}$ plus BA than those in the controls, whereas in genotype 478, the higher $t$-ZR concentrations in samples from trees receiving injections of $\mathrm{BA}$, or $\mathrm{GA}_{4 / 7}$ plus $\mathrm{BA}$ treatment occurred at week 7 (Fig. 5). Increase in endogenous dhZR concentrations was observed only with $\mathrm{GA}_{4 / 7}$ plus BA treatment at week 7 in genotype 276 (Fig. 6). Among isopentenyl (iP)type cytokinins, iPA was the major one. Treatments of $\mathrm{GA}_{4 / 7}$ or $\mathrm{GA}_{4 / 7}$ plus $\mathrm{BA}$ decreased iPA concentrations at week 5 in genotype 276. Significant decreases in iPA concentrations by $\mathrm{GA}_{4 / 7}$ plus BA were also found at weeks 5 and 7 in genotype 478 (Fig. 7). Generally, cytokinin concentrations declined as the season advanced (Figs. 5, 6, 7,8). This trend was more obvious in changes of iPA concentrations (Fig. 7) than others. Concentrations of endogenous $t-Z$, dhZ, Z-O-Glu, and 2iP were generally below quantifiable levels.

The ratio of Z-type cytokinins to iP-type cytokinins was increased by treatments of $\mathrm{BA}$, or $\mathrm{GA}_{4 / 7}$ plus $\mathrm{BA}$ at all time points after PGR injection in genotype 276 (Fig. 8). In genotype 478 , the ratio increased at week 7 in samples of all the treatments. In addition, the treatment of $\mathrm{GA}_{4 / 7}$ plus BA increased the ratio at week 5 (Fig. 8).

Ratio of cytokinins to $A B A$ : The ratios of all quantified cytokinins, including both Z-type and iP-type cytokinins, to $A B A$ were increased by either $\mathrm{GA}_{4 / 7}$ or $\mathrm{GA}_{4 / 7}$ plus $\mathrm{BA}$ treatment in 
genotype 276 one week after injection (Fig. 9), with the largest increases occurring at weeks 3 and 7 . In genotype 478 , the ratio increased only slightly at weeks 5 and/or 7 . Little change occurred in the ratio of cytokinins to ABA in all samples of BA treatment with an only increase seen only in samples of week 3 in genotype 276 (Fig. 9).

\section{Female cone yield per tree following stem-injection of PGRs}

The number of female cones increased significantly $(P<0.05)$ in genotype 276 following stem-injection with $\mathrm{GA}_{4 / 7}$ and $\mathrm{GA}_{4 / 7}$ plus $\mathrm{BA}$. The increases were approximate 1.3 and 1.9 fold respectively, relative to the control (Table 1). No significant change in female cone yield was observed the spring following injection of only BA. In genotype 478 , no significant increase $(P<0.05)$ in female cone yield was caused by any of the PGR treatments tested, although the average number of female cones per tree was increased slightly by steminjection of $\mathrm{GA}_{4 / 7}$ plus BA (Table 1).

\section{Discussion}

Stem-injection of PGRs altered internal levels of some PGRs and altered cone yield in one of two genotypes tested. We will first consider the influence on PGR concentrations in apical buds, the site of cone differentiation, as well as on cone yield.

\section{Changes in GA concentrations in long-shoot buds}

This study reveals the pattern of GA distribution and consumption in long-shoot buds of lodgepole pine after $\mathrm{GA}_{4+7}$ was stem-injected into ramets of two genotypes. Although the tree size was similar and the dosage of $\mathrm{GA}_{4+7}$ injected was the same, concentrations of $\mathrm{GA}$ in the buds differed in the two genotypes one week after $\mathrm{GA}_{4+7}$ injection. Lodgepole pine modified $\mathrm{GA}_{7}$ faster to unidentified product(s) in this study than $\mathrm{GA}_{4}$ initially in this study, whereas $\mathrm{GA}_{4}$ 
declined faster than $\mathrm{GA}_{7}$ in Douglas-fir (Kong et al. 2008). In our present study we also showed variation in GA modification between the two genotypes. Genotype 276 presumably metabolized GAs faster than genotype 478 , because both total $\mathrm{GA}_{4+7}$ amount and the ratio of $\mathrm{GA}_{7}$ to $\mathrm{GA}_{4}$ in the buds were lower in genotype 276 than 478 after $\mathrm{GA}_{4+7}$ injection. There are many studies of cone induction, but few studies of the effect on hormone physiology, such as turnover in endogenous phytohormones after cone induction treatments. In Douglas-fir, $\mathrm{GA}_{4+7}$ concentration declined dramatically in the first three weeks after GA injection (Kong et al. 2008), whereas we found high concentrations of GA were seen over a relatively longer period of time in this study of long-shoot buds of lodgepole pine. The major active GAs identified in conifers include gibberellins $A_{1}, A_{3}, A_{4}, A_{7}$ and $A_{9}$ (Moritz et al. 1990-; Wang et al. 1995; MacMillan 2001). In this study, unquantifiable $\mathrm{GA}_{1}$ and $\mathrm{GA}_{3}$ might be due to their faster turnover.

\section{Effects of injected PGRs on endogenous ABA}

Injection of $\mathrm{GA}_{4+7}$, but not $\mathrm{BA}$, decreased endogenous $\mathrm{ABA}$ and $\mathrm{ABA}$ metabolites in longshoot buds in lodgepole pine. It is well known that a range of GA structures is associated with functions promoting germination, growth, and flowering, whereas $A B A$ inhibits these processes. Therefore, GA and ABA play antagonistic roles regulating a number of developmental processes (Reviewed by Weiss and Ori 2007). As we expected, endogenous ABA levels were reduced by GA injection in this study, which was similar to the results with paste treatments of lodgepole pine branches (Kong et al. 2016). In the present study, declines in ABA concentrations did not lead to increases in ABA-GE, a major ABA metabolite (Cutler and Krochko 1999), as occurred in Douglas-fir when the season advanced from winter to summer (Kong et al. 2009). In lodgepole pine, injections of $\mathrm{GA}_{4+7}$ alone or in 
combination with $\mathrm{GA}_{4+7}$ and $\mathrm{BA}$ also reduced levels of both $\mathrm{ABA}$ and $\mathrm{ABA}-\mathrm{GE}$ relative to controls. The lowered ABA levels may have been the result of reduced ABA synthesis or elevated ABA synthesis or elevated ABA metabolism via several other metabolic pathways (Nambara and Marion-Poll 2005).

\section{Effects of injected PGRs on endogenous cytokinins}

Changes of phytohormone profiles after PGR injection differed between genotypes and PGR treatments. In both genotype 276 and 478, injection of GA plus BA showed stronger effects on concentrations of $t-Z R$, and iPA than GA injection alone. Also, dhZR increased in genotype 276 in response to injection of GA plus BA. This is similar to result achieved by application of BA to Pinus radiata, which resulted in an increase in concentrations of a number of endogenous cytokinins (Montalbán et al. 2013). In spruces, root girding decreased cytokinin biosynthesis and enhanced effects of exogenousally applied $\mathrm{GA}_{4+7}$ on cone yield, whereas exogenously applied BA reduced these effects (Kinet et al. 1993; Smith and Greenwood 1995). Wakushima (2004) reported significant effects of exogenousally applied BA on differentiation of cone buds in both Japanese red pine and black pine. Our research revealed that $\mathrm{GA}_{4+7}$, especially the combination of $\mathrm{GA}_{4+7}$ and $\mathrm{BA}$, had a greater impact on other endogenous hormones when compared with application of cytokinin alone in lodgepole pine. These results confirm our previous research with paste treatments in lodgepole pine (Kong et al. 2016) in which responses to a particular PGR treatment differed between species and between genotypes of the same species (Kong and von Aderkas 2007). Endogenous phytohormone concentrations were increased by PGR treatments that may in turn enhance yield of cones in different genotypes.

In genotype 276, the ratio of Z-type to iP-type cytokinins was altered by PGR injection. 
This was largely a result of increases in $t$-ZR concentration and decrease in iPA concentration. The highest increase in ratios was caused by injection of $\mathrm{GA}_{4+7}$ plus $\mathrm{BA}$. Morris et al. (1990) reported that Z-type cytokinin concentration was relatively higher in female cone buds, whereas the concentration of iPA was higher in male cone buds. In conifers, gender determination of cone buds was affected by application of a paste of BA to buds (Wakushima 2004), or $\mathrm{GA}_{4+7}$ plus TDZ (Kong et al. 2016). The importance of cytokinins in cone bud differentiation of Pinaceae species is also supported by previous reports (Imbault et al. 1988; Pilate et al. 1990; Zhang et al. 2003). In the results that we report here, zeatin concentrations were generally low, often below quantifiable levels, implying that there is either a very small pool of zeatin or a rapid turnover of $Z$ to $Z R$, or both; a situation which may be similar to one seen for Douglas-fir (Kong et al. 2009). Bonhomme et al. (2000) reported that the combination of $\mathrm{GA}_{3}$ and $\mathrm{BA}$ resulted in greater expression of SaMADS $\mathrm{A}$, a gene involved in regulation of the floral transition in a herbaceous dicot, Sinapis alba, than either $\mathrm{GA}_{3}$ or $\mathrm{BA}$ on their own. In our study, the response occurred after stem-injection of $\mathrm{GA}_{4+7}$ plus $\mathrm{BA}$ was similarly more effective than either PGR on its own.

\section{Effects of injected PGRs on ratios of endogenous phytohormones}

Although the mechanism is not clear, high ratios of Z-type cytokinins to iP-type cytokinins were assumed to be related to higher vigour in Pinus radiata (Valdés et al. 2002, 2003) and also to better reproductive capability in Douglas-fir (Morris et al. 1990). These ratios were increased by paste treatments of $\mathrm{GA}_{4+7}$ in combination with TDZ resulted in much higher numbers of female cones (Kong et al. 2016). Injection of PGRs also increased the ratio of total cytokinins to ABA. The largest increases were due to the combination of both GA and BA. The ratio between ABA and cytokinins in xylem sap are postulated to play an important 
role in stress signalling (Alvarez et al. 2008, Schachtman and Goodger 2008). The higher ratios of cytokinins to ABA may thus favour faster vegetative growth and female cone formation (Kong et al. 2011, 2012). In the results reported here, higher concentrations of cytokinins and lower concentrations of ABA were found in the genotype of a good cone producer than in the poor cone producer, in keeping with previously published studies on lodgepole pine (Kong et al. 2011).

\section{Optimizing cone induction methods on genotype responses}

Our results demonstrated some correlations between the effects shown by endogenous phytohormones and a set of cone induction results for two genotypes of lodgepole pine. Genotype 276 showed increases in both ratios, i.e. Z- to iP- cytokinins, and the total cytokinins to ABA. Specifically, treatment with $\mathrm{GA}_{4+7}$ and $B A$ were effective in modifying endogenous cytokinins and $\mathrm{ABA}$ and increasing cone induction. In contrast, no effects were observed with genotype 478. Application of BA on its own had little effect on hormone profiles and cone induction in lodgepole pine.

Even though significant changes were found in hormone concentrations in genotype 276 , these changes were not as great as those caused by paste treatment to long-shoot buds with GA and cytokinin (Kong et al. 2016). This fact, in addition to little effect on both phytohormone profiles and cone yield in genotype 478, suggested that higher dosages of PGRs might be needed to optimize female cone bud yields in further experiments.

In conclusion, our results reveal different responses, i.e. changes in concentrations of endogenous phytohormones and some of their metabolites, as a result of stem-injection of PGRs in two lodgepole pine genotypes. Effects of PGRs on phytohormone profiles together with different cone induction results point to an involvement of higher concentrations of 
endogenous Z-type cytokinins and lower level of ABA and metabolites in long-shoot buds may be causally associated in cone bud formation. Stem injection of $\mathrm{GA}_{4 / 7}$ and cytokinin, BA, could be an effective method for operational use to increase female cone yield in particular genotypes, and subsequently seed production in lodgepole pine seed orchards.

\section{Author contribution statement}

Lisheng Kong: experiment design, treatment application, data analysis, MS preparation, Patrick von Aderkas project PI, experiment design, MS preparation L. Zaharia: phytohormone analysis.

\section{Acknowledgments}

We gratefully acknowledge the financial support of the British Columbia Ministry of Forests, Lands and Natural Resource Operations, as well as the Forest Genetics Council of British Columbia. This project was also supported by the Discovery Grant Program of the Natural Sciences and Engineering Research Council of Canada. Assistance from Tim Lee, Tia Wagner and Dan Gaudet (Vernon Seed Orchard Company), Julia Gill, Dr. Cunxu Zhang, and Meaghan Duke (University of Victoria), Monika Lafond, Vera Čekić, Stacey Owen, and Dr. Suzanne Abrams (NRCC-PBI) is gratefully acknowledged.

\section{Compliance with ethical standards}

Conflict of interest: the authors declare that they have no conflict of interest.

\section{References}

Alvarez S, Marsh EL, Schroeder SG, Schachtman DP (2008) Metabolomic and proteomic changes in the xylem sap of maize under drought. Plant Cell Environ. 31:325-340.

Amman GD, Schmitz RF (1988) Mountain pine beetle: lodgepole pine interactions and strategies for reducing tree losses. Ambio 17:62-68

Bonhomme F, Kurz B, Melzer S, Bernier G, Jacqmard A (2000) Cytokinin and gibberellin 
activate SaMADS A, a gene apparently involved in regulation of the floral transition in Sinapis alba. Plant $\mathrm{J} 24: 103-111$

Bonnet-Masimbert M (1987) Floral induction in conifers: a review of available techniques. For Ecol Manag 19:135-146

Chiwocha SDS, Abrams SR, Ambrose SJ, Cutler AJ, Loewen M, Ross ARS, Kermode AR (2003) A method for profiling classes of plant hormones and their metabolites using liquid chromatography-electrospray ionization tandem mass spectrometry: analysis of hormone regulation of thermodormancy of lettuce (Lactuca sativa L.) seeds. Plant J 35:405-417

Chiwocha SDS, Cutler AJ, Abrams SR, Ambrose SJ, Yang J, Ross ARS, Kermode AR (2005) The etr1-2 mutation in Arabidopsis thaliana affects the abscisic acid, auxin, cytokinin and gibberellin metabolic pathways during maintenance of seed dormancy, moist-chilling and germination. Plant J 42:35-48

Cutler AJ, Krochko JE (1999) Formation and breakdown of ABA. Trends Plant Sci 4:472-478

Fettig CJ, Gibson KE, Munson AS, Negrón JF (2014) Cultural practices for prevention and mitigation of mountain pine beetle infestations. For Sci 60:450-63

Herrera CM, Jordano P, Guitián J, Traveset A (1998) Annual variability in seed production by woody plants and the masting concept: reassessment of principles and relationship to pollination and seed dispersal. Am Naturalist 152:576-594

Imbault N, Tardieu I, Joseph C, Zaerr JB, Bonnet-Masimbert M (1988) Posible role of isopentenyladenine and isopentenyladenosine in flowering of Pseudotsuga menziesii: endogenious variations and exogenous applications. Plant Physiol Biochem 26:289-295

Kinet JM, Lejeune P, Bernier G (1993) Shoot-root interactions during floral transition: a possible role for cytokinins. Environ Exp Bot 33:459-469

Kong L, von Aderkas P (2007) Genotype effects on ABA consumption and somatic embryo maturation in interior spruce (Picea glauca x engelmanni). J Exp Bot 58:1525-1531

Kong L, Abrams SR, Owen S, Graham H, von Aderkas P (2008) Phytohormones and their metabolites during long shoot development in Douglas-fir following cone induction by gibberellin injection. Tree Physiol 28:1357-1364

Kong L, Abrams SR, Owen S, Van Niejenhuis A, von Aderkas P (2009) Dynamic changes in concentrations of auxin, cytokinin, ABA and selected metabolites in multiple genotypes of Douglas-fir (Pseudotsuga menziesii) during a growing season. Tree Physiol 29:183190 
Kong L, von Aderkas P, Owen SJ, Wagner T, Abrams SR (2011) Comparison of endogenous cytokinins, ABA and metabolites during female cone differentiation in low and high coneproducing genotypes of lodgepole pine. Trees 25:1103-1110

Kong L, von Aderkas P, Zaharia I, Abrams SR, Lee T, Woods J (2012) Analysis of phytohormone profiles during male and female cone initiation and early differentiation in long-shoot buds of lodgepole pine. J Plant Growth Regul 31:478-489

Kong L, von Aderkas P, Zaharia I (2016) Effects of exogenously-applied gibberellins and thidiazuron on phytohormone profiles of long shoot buds and cone gender determination in lodgepole pine. J Plant Growth Regul 35:172-182

MacMillan JJ (2001) Occurrence of gibberellins in vascular plants, fungi, and bacteria. Plant Growth Regul 20:387-442.

Marquard RD, Hanover JW (1984a) Sexual zonation in the crown of Picea glauca and flowering response to exogenous GA4/7. Can J For Res 14:27-30

Marquard, RD Hanover JW (1984b) Relationship between gibberellin A4/7 concentration, time of treatment, and crown position on flowering of Picea glauca. Can J For Res $14: 547-553$

McDougal FW (1973) The importance of lodgepole pine in Canada. Proceedings of the Symposium on Management of Lodgepole Pine Ecosystems. Washington State University, Pullman, pp 9-11

Montalbán IA, Nova’k O, Rolc`ik J, Strnad M, Moncalea'n P (2013) Endogenous cytokinin and auxin profiles during in vitro organogenesis from vegetative buds of Pinus radiata adult trees. Physiol Plant 148:214-231

Moritz, T, Philipson JJ, Odén PC (1990) Quantitation of gibberellins $A_{1}, A_{3}, A_{4}, A_{9}$, and a putative $A_{9}$-conjugate in grafts of Sitka spruce (Picea sitchensis) during the period of shoot elongation. Plant Physiol 93:1476-1481.

Morris JW, Doumas P, Morris RO, Zaerr JB (1990) Cytokinins in vegetative and reproductive buds of Pseudotsuga menziesii. Plant Physiol 93:67-71

Nambara E, Marion-Poll A (2005) Abscisic acid biosynthesis and catabolism. Annu Rev Plant Physiol Plant Mol Biol 56:165-185 
Pharis RP, Webber JE, Ross SD (1987) The promotion of flowering in forest trees by gibberellin A4/7 and cultural treatments: a review of the possible mechanisms. For Ecol Manag 19:65-84.

Pilate G, Sotta B, Maldiney R, Bonnet-Masimbert M, Miginiac E (1990) Endogenous hormones in Douglas-fir trees induced to flower by gibberellin $\mathrm{A}_{4 / 7}$ treatment. Plant Physiol Biochem 28:359-366

Ross SD, Pharis RP (1987) 3. Control of sex expression in conifers. Plant Grow Regul 6:3760

Schachtman DP, Goodger JQ (2008) Chemical root to shoot signaling under drought. Trends Plant Sci 13:281-287.

Smith RF, Greenwood MS (1995) Effects of gibberellin $A_{4 / 7}$, root pruning, and cytokinins on seed- and pollen cone production in black spruce (Picea mariana). Tree Physiol 15:457466

Tompsett PB (1977) Studies of growth and flowering in Picea sitchensis (Bong.) Carr. 1. Effects of growth regulator applications to mature scions on seedling rootstocks. Ann Bot 41:1171-1178

Valdés AE, Fernández B, Centeno ML (2003) Alterations in endogenous levels of cytokinins following grafting of Pinus radiata support ratio of cytokinins as an index of ageing and vigour. J Plant Physiol 160:1407-1410

Valdés AE, Centeno ML, Espinel S, Fernández B (2002) Could plant hormones be the basis of maturation indices in Pinus radiata? Plant Physiol Biochem 40:211-216

Wakushima S (2004) Promotion of female strobili flowering and seed production in two Japanese pine species by 6-benzylaminopurine (BAP) paste application in a field seed orchard. J Plant Growth Regul 23:135-145

Wang Q, Little CHA, Moritz T, Odén PC (1995) Effects of prohexadione on cabial and longitudinal growth and the levels of endogenous gibberellins $A_{1}, A_{3}, A_{4}$, and $A_{9}$ and indole-3-acetic acid in Pinus sylvestris shoots. J Plant Growth Regul 14:175-181.

Weiss D, Ori N (2007) Mechanisms of cross talk between gibberellin and other hormones. Plant Physiol 144:1240-1246

Zaerr JB, Bonnet-Masimbert M (1987) Cytokinin level and flowering in Douglas-fir. For Ecol Manage 19:115-120 
Zhang H, Horgan KJ, Reynolds PHS, Jameson PE (2003) Cytokinins and bud morphology in Pinus radiate. Physiol Plant 117:264-269 


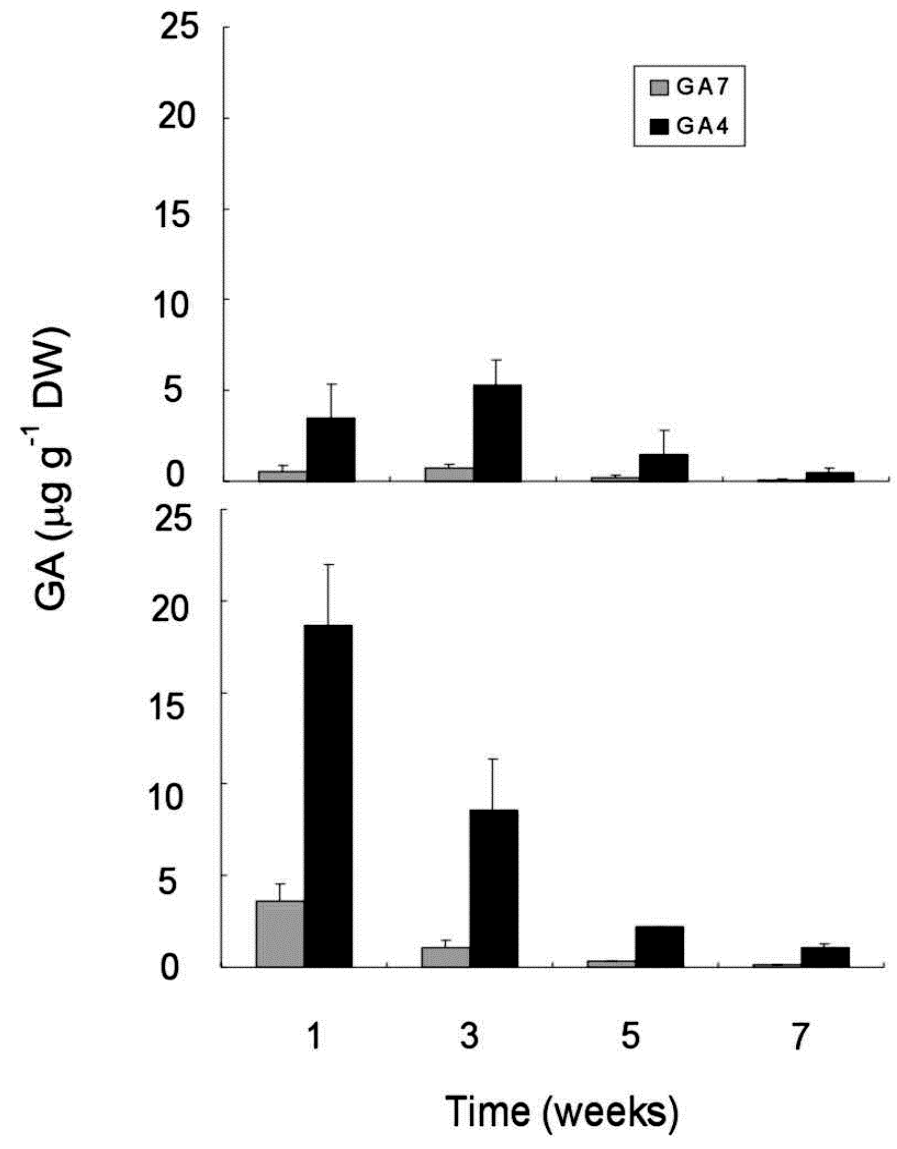

Fig. 1 Changes in concentrations of gibberellins in long-shoot buds following stem injections of $\mathrm{GA}_{4+7}(40 \mathrm{mg}$ per ramet) for each lodgepole pine ramet in genotype 276 (upper histogram) or genotype 478 (lower histogram), mean $\pm S E, n=3$. 


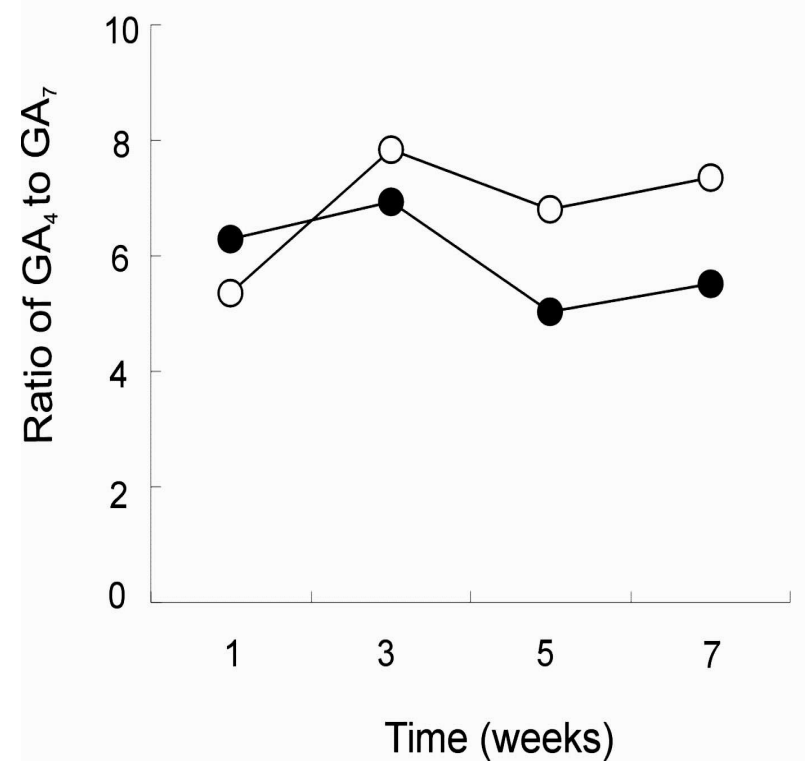

Fig. 2 Changes in the ratios of $\mathrm{GA}_{4}$ to $\mathrm{GA}_{7}$ in long-shoot buds following stem injections of $\mathrm{GA}$ (40 mg per ramet) for each lodgepole pine ramet in genotype 276 (solid circles) or genotype 478 (open circles), mean, $n=3$. 



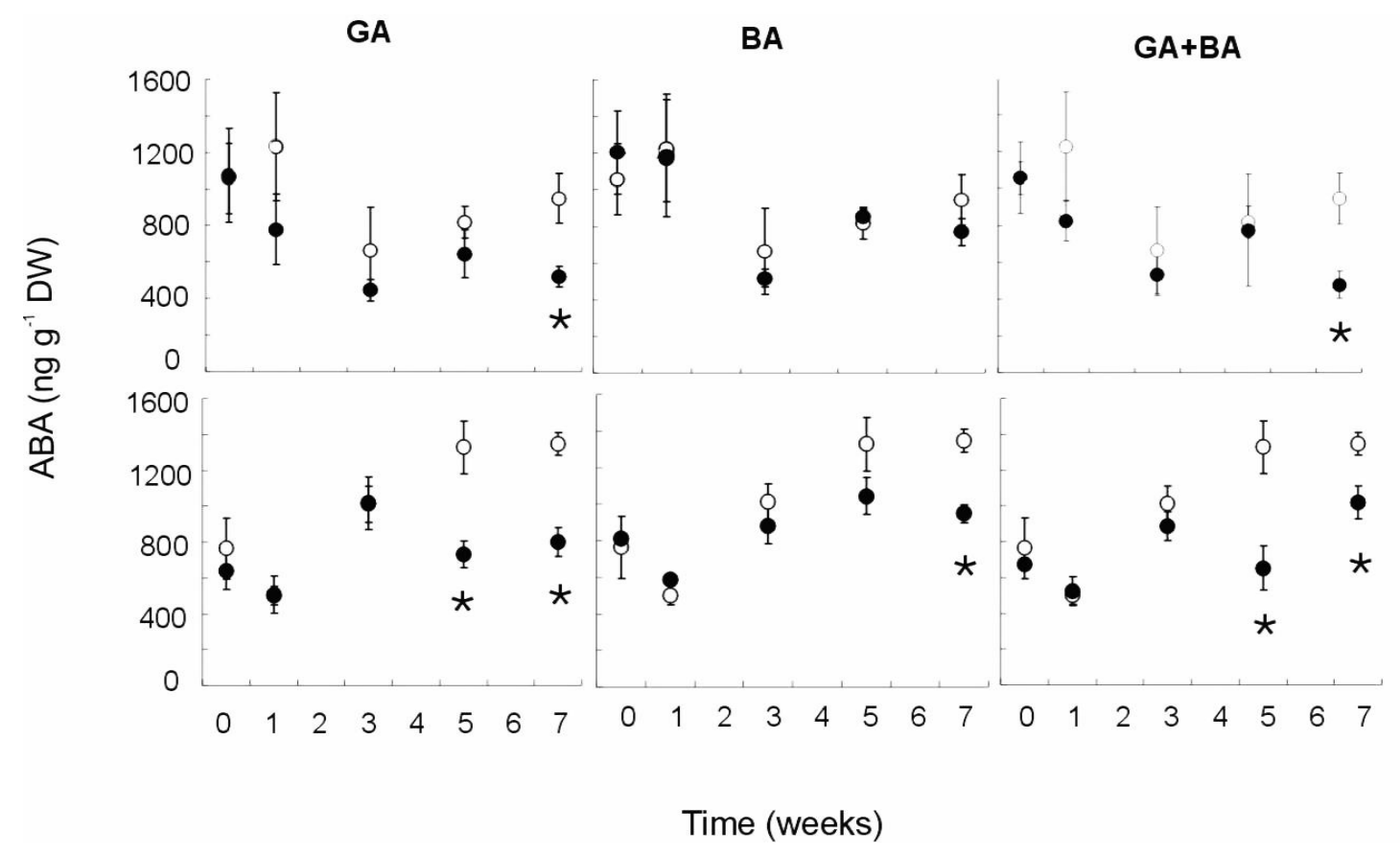

Fig. 3 Changes in concentrations of $A B A$ in long-shoot buds following stem injections of 40 $\mathrm{mg} \mathrm{GA}_{4+7}$ and/or $40 \mathrm{mg} \mathrm{BA}$ for each lodgepole pine ramet. PGRs were injected into the trees in genotype 276 (upper row of graphs) or genotype 478 (lower row of graphs), mean \pm $S E, \mathrm{n}=3$. Open circles indicate control without PGR injection. Solid circles indicate PGR treatment. The asterisk indicates a significant difference, at the $P<0.05$ levels, to the control at each application time point. 


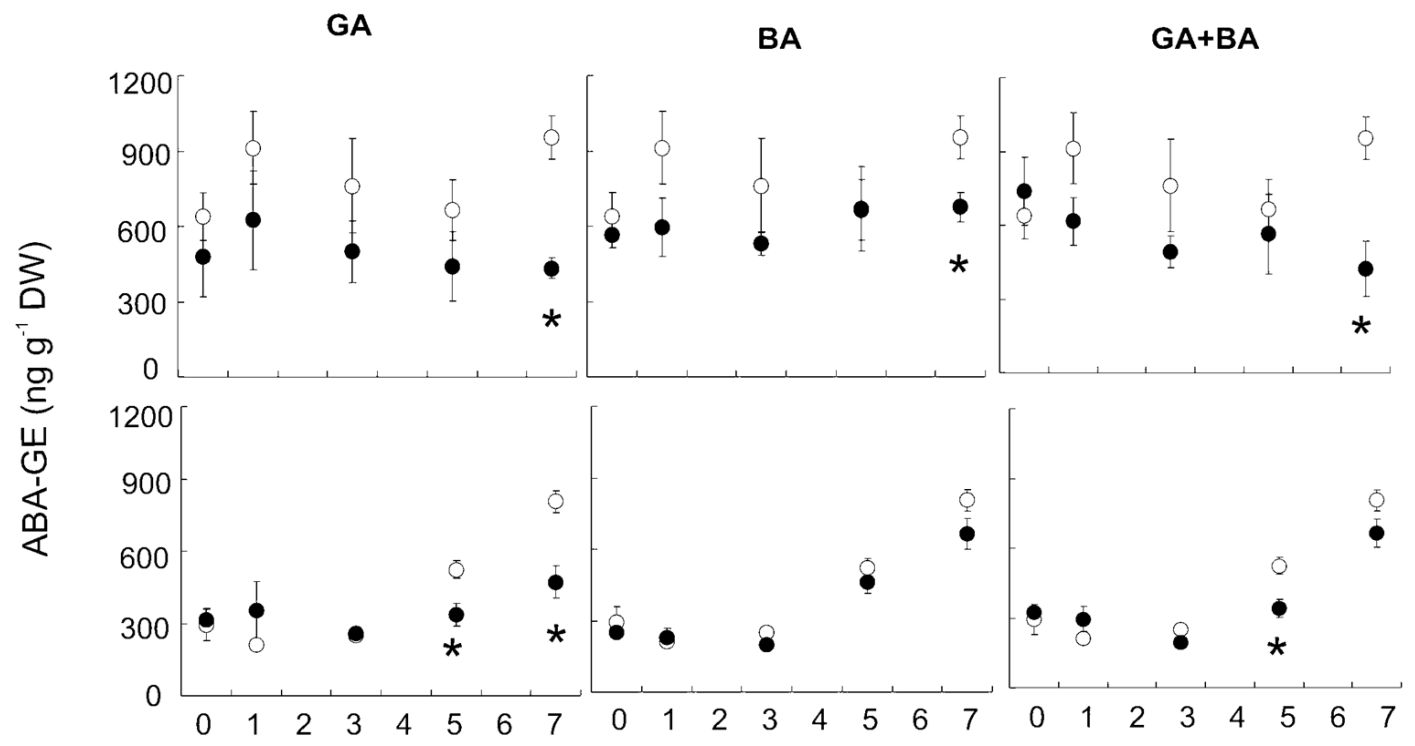

Time (weeks)

Fig. 4 Changes in concentrations of ABA-GE in long-shoot buds following stem injections of $40 \mathrm{mg} \mathrm{GA}_{4+7}$ and/or $40 \mathrm{mg}$ BA for each lodgepole pine ramet. PGRs were injected into the trees in genotype 276 (upper row of graphs) or genotype 478 (lower row of graphs), mean \pm $S E, \mathrm{n}=3$. Open circles indicate control (0 mg PRG). Solid circles indicate PGR treatment. The asterisk indicates a significant difference, at the $P<0.05$ level, to the control at each application time point. 


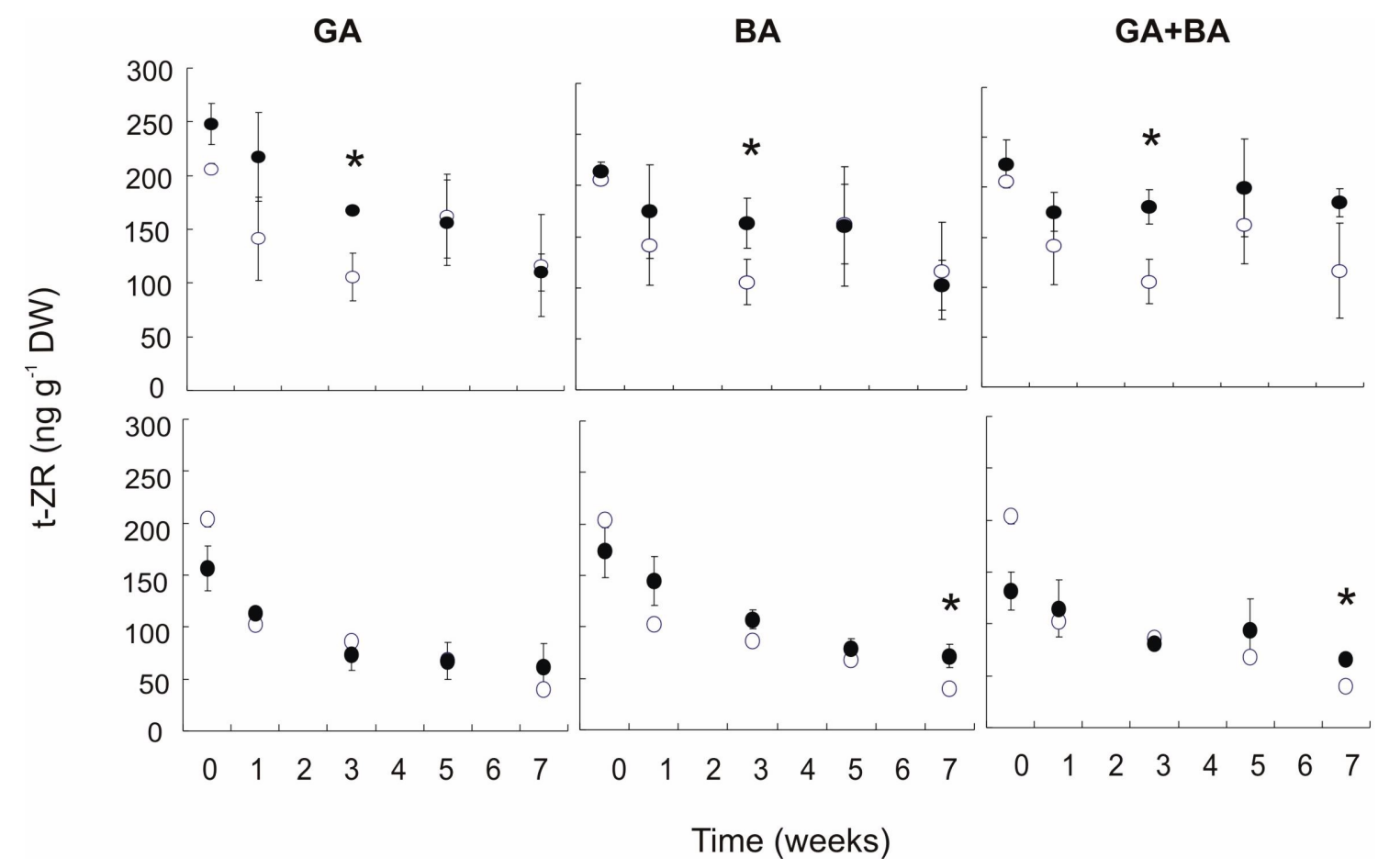

Fig. 5 Changes in concentrations of t-ZR in lodgepole pine long-shoot buds following stem injections of $40 \mathrm{mg} \mathrm{GA}_{4+7}$ and/or $40 \mathrm{mg}$ BA for each lodgepole pine ramet. PGRs were injected into the trees in genotype 276 (upper row of graphs) or genotype 478 (lower row of graphs), mean $\pm S E, n=3$. Open circles indicate control without PGR injection. Solid circles indicate PGR treatment. The asterisk indicates a significant difference, at the $P<0.05$ levels, to the control at each application time point. 


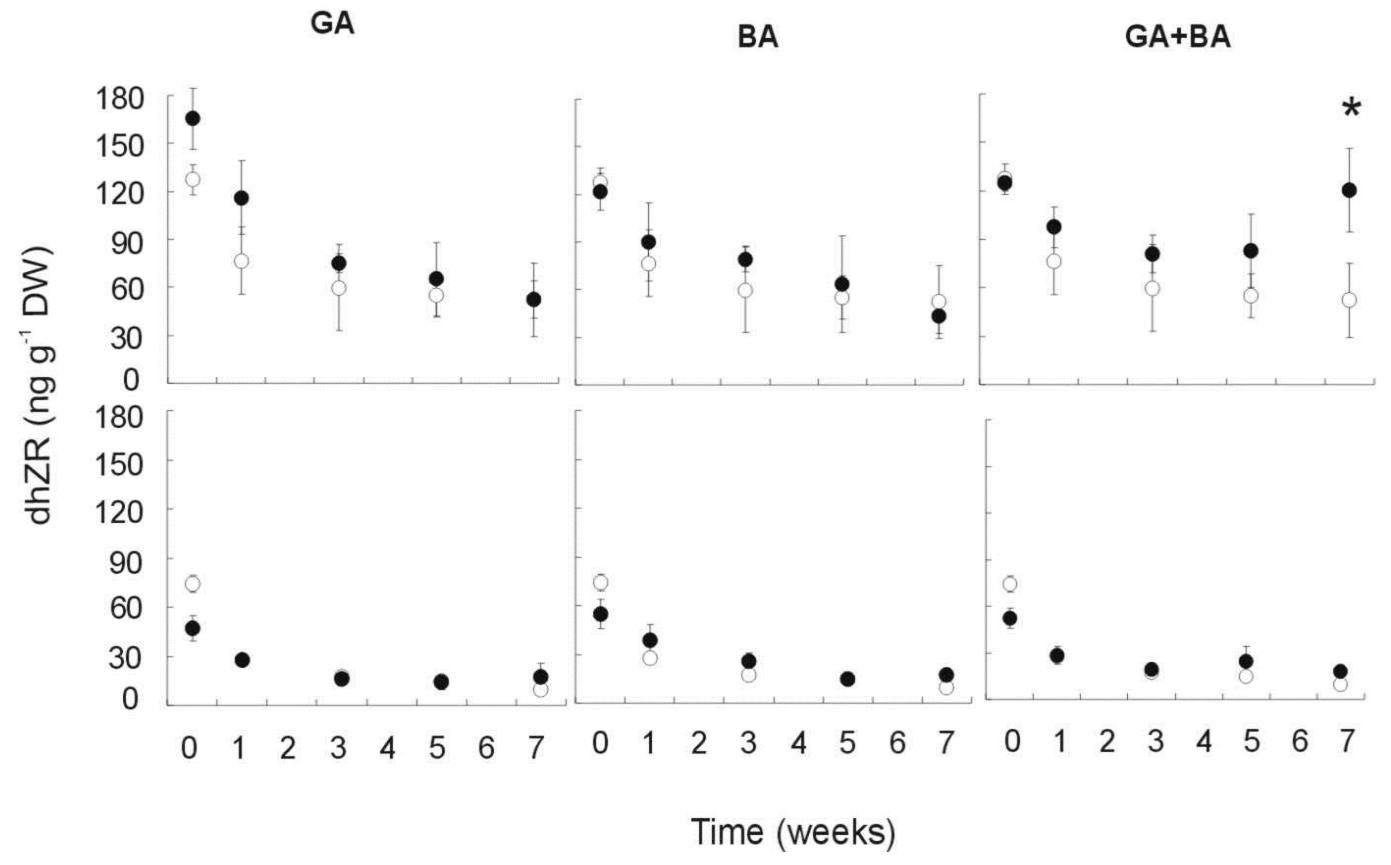

Fig. 6 Changes in concentrations of dhZR in lodgepole pine long-shoot buds following stem injections of $40 \mathrm{mg} \mathrm{GA} 4+7$ and/or $40 \mathrm{mg}$ BA for each lodgepole pine ramet. PGRs were injected into the trees in genotype 276 (upper row of graphs) or genotype 478 (lower row of graphs), mean $\pm S E, n=3$. Open circles indicate control without $P G R$ injection. Solid circles indicate PGR treatment. The asterisk indicates a significant difference, at the $P<0.05$ levels, to the control at each application time point. 


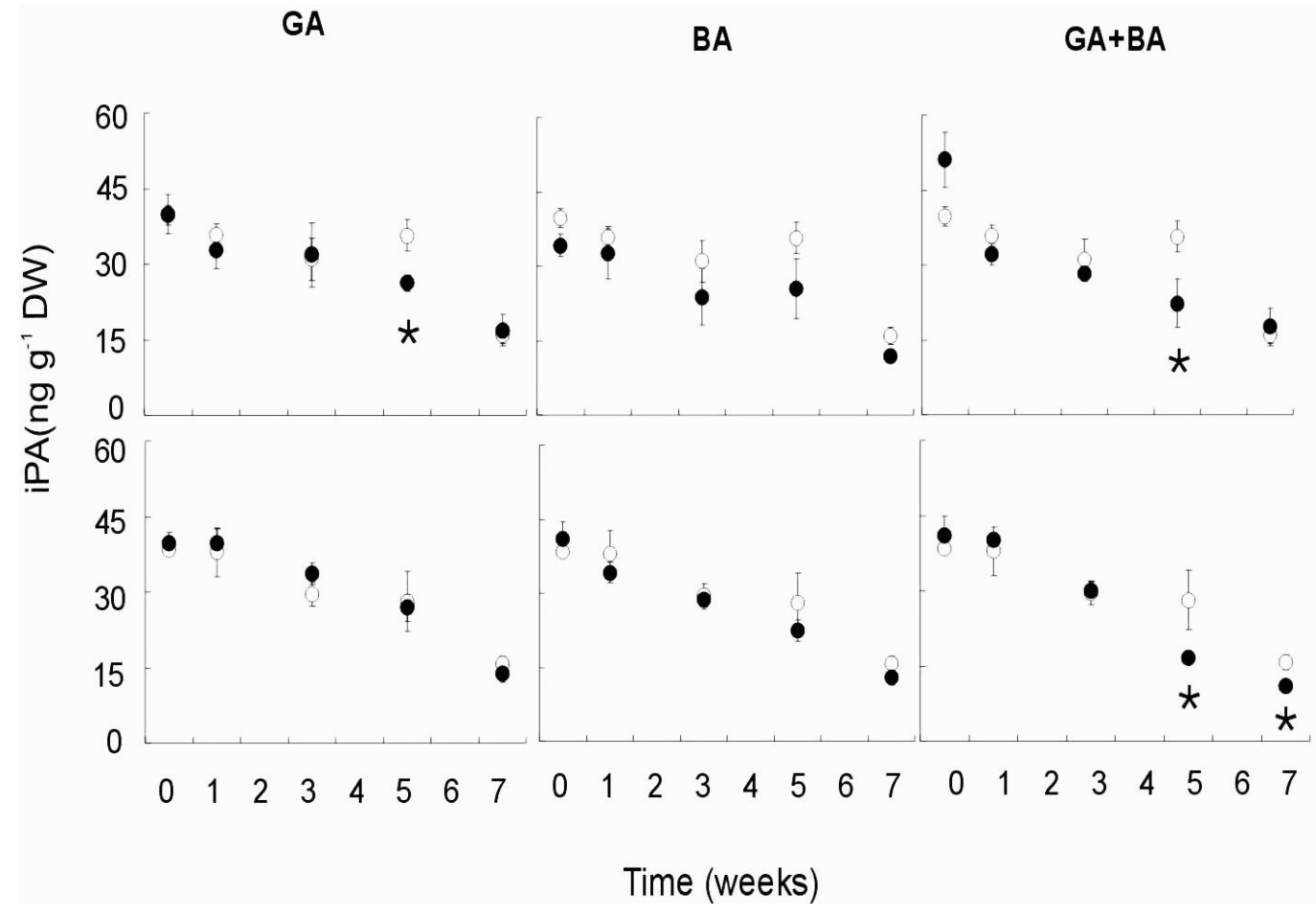

Fig. 7 Changes in concentrations of iPA in lodgepole pine long-shoot buds following stem injections of $40 \mathrm{mg} \mathrm{GA} \mathrm{m}_{4+7}$ and/or $40 \mathrm{mg}$ BA for each lodgepole pine ramet. PGRs were injected into the trees in genotype 276 (upper row of graphs) or genotype 478 (lower row of graphs), mean $\pm S E, n=3$. Open circles indicate control without PGR injection. Solid circles indicate PGR treatment. The asterisk indicates a significant difference, at the $P<0.05$ levels, to the control at each application time point. 
GA

BA

$G A+B A$

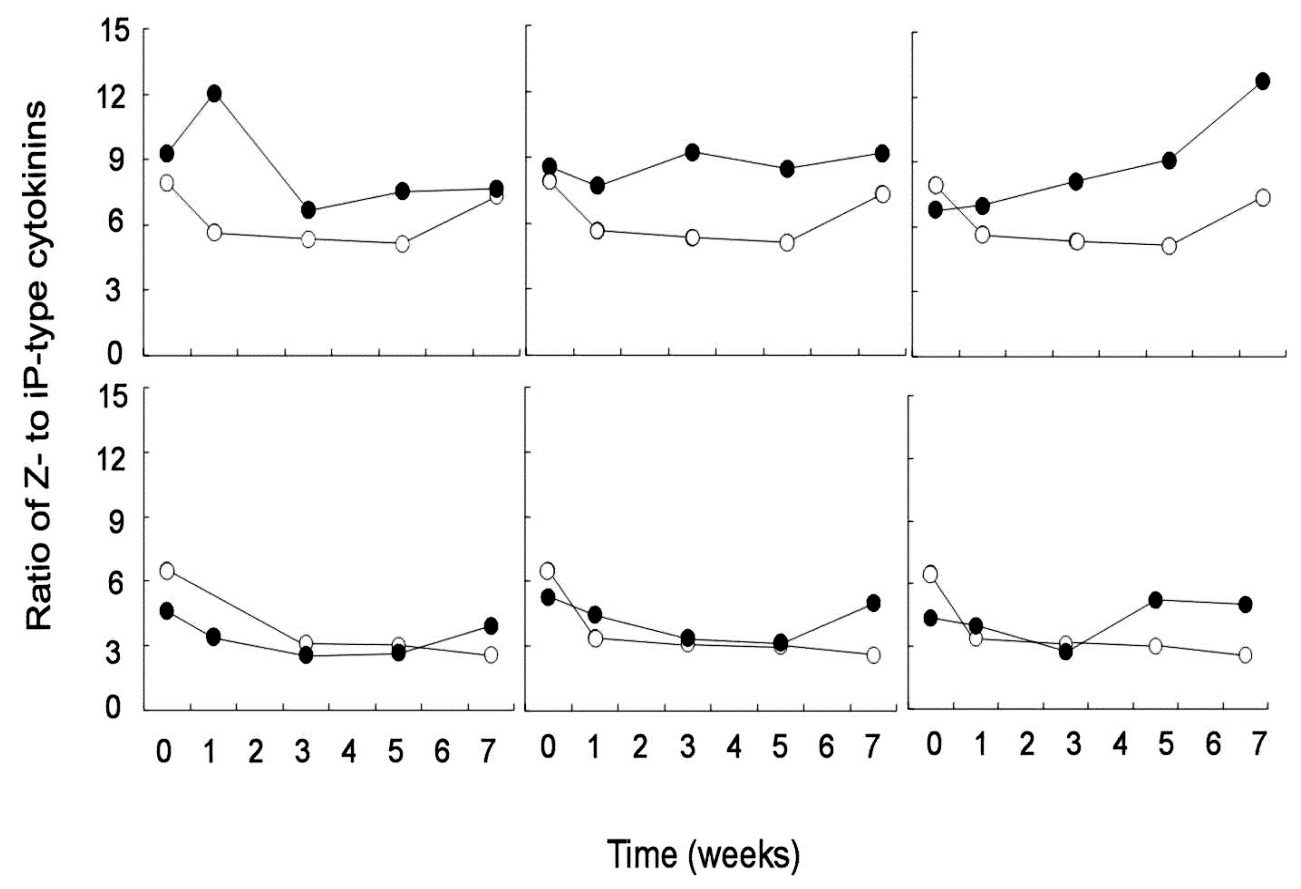

Fig. 8 Changes in ratios of Z-type to iP-type cytokinins in lodgepole pine long-shoot buds following stem injections of $40 \mathrm{mg} \mathrm{GA} \mathrm{m}_{4+7}(\mathrm{GA}), 40 \mathrm{mg}$ BA or a combination of both $\mathrm{GA}$ and BA for each ramet in genotype 276 (upper row of graphs) and genotype 478 (lower row of graphs), mean of three ramets. Open circles indicate control. Solid circles indicate PGR treatment. Mean, $\mathrm{n}=3$. 


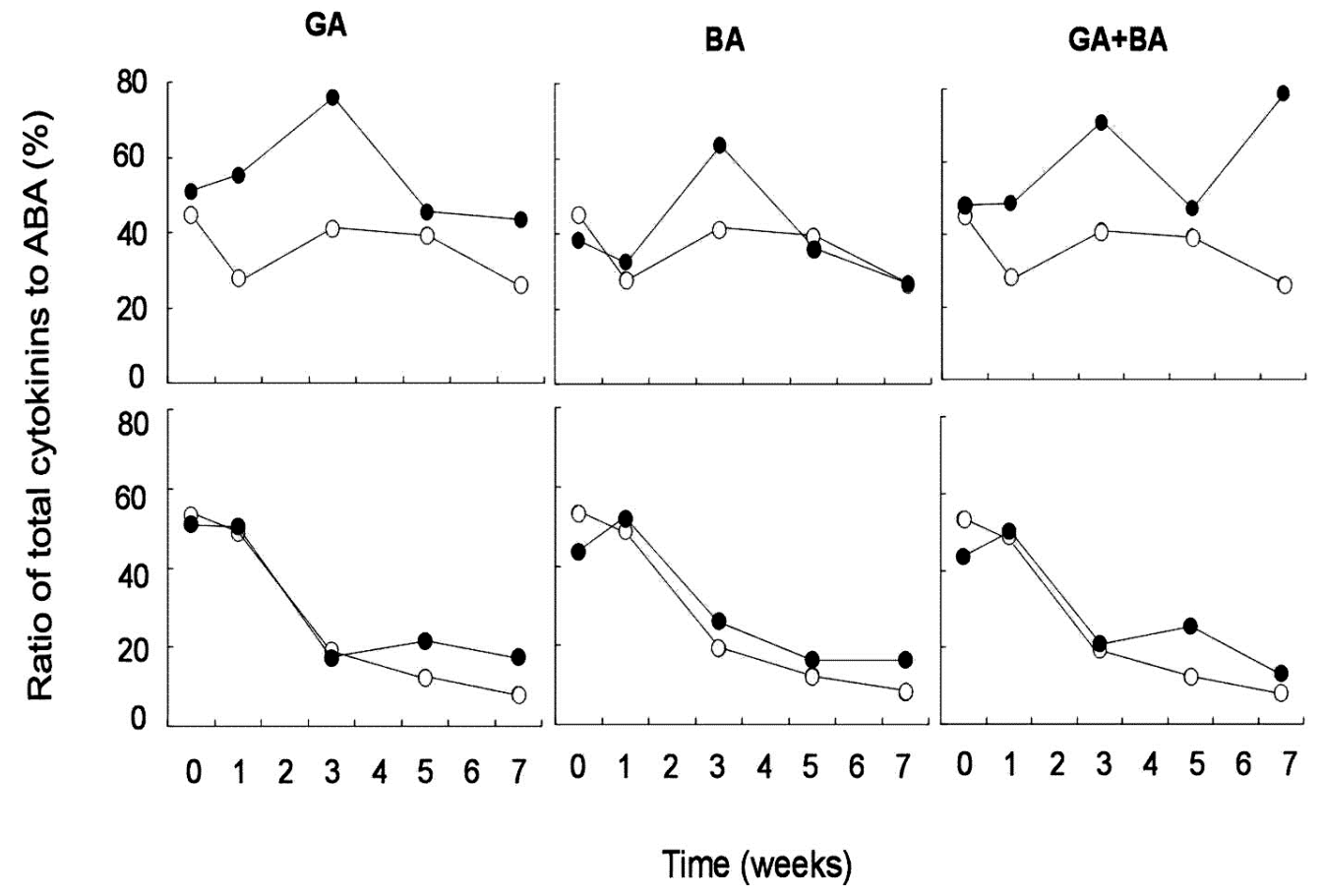

Fig. 9 Changes in ratios of total cytokinins to $A B A$ in lodgepole pine long-shoot buds following stem injections of $40 \mathrm{mg} \mathrm{GA} 4+7,40 \mathrm{mg} \mathrm{BA}$ or a combination of both $\mathrm{GA}$ and BA for each ramet in genotype 276 (upper row of graphs) and genotype 478 (lower row of graphs), mean of three ramets. Open circles indicate control. Solid circles indicate PGR treatment. Mean, $n=3$. 
Table 1 Effects of stem-injection of plant growth regulators on female cone yield (number of cones per ramet) in lodgepole pine. Mean $\pm S E, \mathrm{n}=3$ ramets.

\begin{tabular}{|c|c|c|c|c|}
\hline & Control & GA & BA & $\mathrm{GA}+\mathrm{BA}$ \\
\hline Genotype 276 & $125.3 \pm 11.2$ & $165.8 \pm 8.9^{*}$ & $130.1 \pm 13.3$ & $238.2 \pm 26.4^{*}$ \\
\hline Genotype 478 & $106.2 \pm 10.4$ & $117.6 \pm 11.2$ & $113.7 \pm 8.6$ & $125.7 \pm 13.1$ \\
\hline
\end{tabular}

${ }^{*} P<0.05$, between the treatment and its control. 